\title{
PERUMUSAN STRATEGI DINAS PARIWISATA DAN KEBUDAYAN KABUPATEN LOMBOK TENGAH UNTUK MENINGKATKAN KUNJUNGAN WISATAWAN DI PANTAI SELATAN LOMBOK TENGAH
}

\author{
Khairunnisa ${ }^{1}$, Baiq Handayani Rinuastuti², Lalu M. Furkan ${ }^{3}$ \\ ${ }^{1}$ Program Magister Manajemen, Universitas Mataram, Indonesia \\ E-mail:nisahbasri@gmail.com \\ 2Program Magister Manajemen, Universitas Mataram, Indonesia \\ E-mail:hrianuastuti@yahoo.com \\ 3 Program Magister Manajemen, Universitas Mataram, Indonesia \\ E-mail:_lalu.furkan@gmail.com
}

\begin{tabular}{|c|c|}
\hline ARTICLE INFO & ABSTRACT \\
\hline $\begin{array}{l}\text { Keywords : } \\
\text { SWOT Analysis, Strategy Formulation, } \\
\text { Strategic management, Tourism } \\
\text { How to cite: } \\
\text { Khairunnisa., Rinuastuti, Baiq Handayani., } \\
\text { Furkan, Lalu Muhammad (2018). } \\
\text { Perumusan Strategi Dinas Pariwisata Dan } \\
\text { Kebudayan Kabupaten Lombok Tengah } \\
\text { Untuk Meningkatkan Kunjungan } \\
\text { Wisatawan Di Pantai Selatan Lombok } \\
\text { Tengah. JMM UNRAM, 7(2), 50 - } 59 \\
\text { DOI: } \\
\text { 10.29303/jmm.v7i2.317 }\end{array}$ & $\begin{array}{l}\text { This study aimed at formulating the strategy proposed to the } \\
\text { District Agency of Tourism and Culture of Central Lombok } \\
\text { to increase tourist visits. This research is using a qualitative } \\
\text { approach within case studies. Informants were selected } \\
\text { through purposive sampling. Two informants were selected } \\
\text { from the Agency of Tourism and Culture of Central Lombok; } \\
\text { namely the Head of Agency and the Field Head of Marketing } \\
\text { and Promotion. The research showed that the findings } \\
\text { obtained from the analysis using SWOT and data reduction, } \\
\text { the tourism in the south coast of Central Lombok has good } \\
\text { strength and opportunity. The research recommends that in } \\
\text { increasing numbers tourist visits the Agency of Tourism } \\
\text { and Culture of Central Lombok conduct four better } \\
\text { strategies namely forward integration (increasing control of } \\
\text { tourist suppliers), market penetration (intensive promotion), } \\
\text { concentric diversification (add tourism products such as } \\
\text { water sports, traditional restaurants, hotels), and product } \\
\text { development (current products modification). Since there } \\
\text { were still problems in Human Resource, the Agency of } \\
\text { Tourism and Culture of Central Lombok should pay more } \\
\text { attention to human resources by developing human resource } \\
\text { products. } \\
\text { Penelitian ini bertujuan untuk merumuskan usulan strategi } \\
\text { bagi Dinas Pariwisata dan Kebudayaan Lombok Tengah }\end{array}$ \\
\hline
\end{tabular}




\section{NATIONALLY ACCREDITED JOURNAL - DECREE NO. 21/E/KPT/2018}

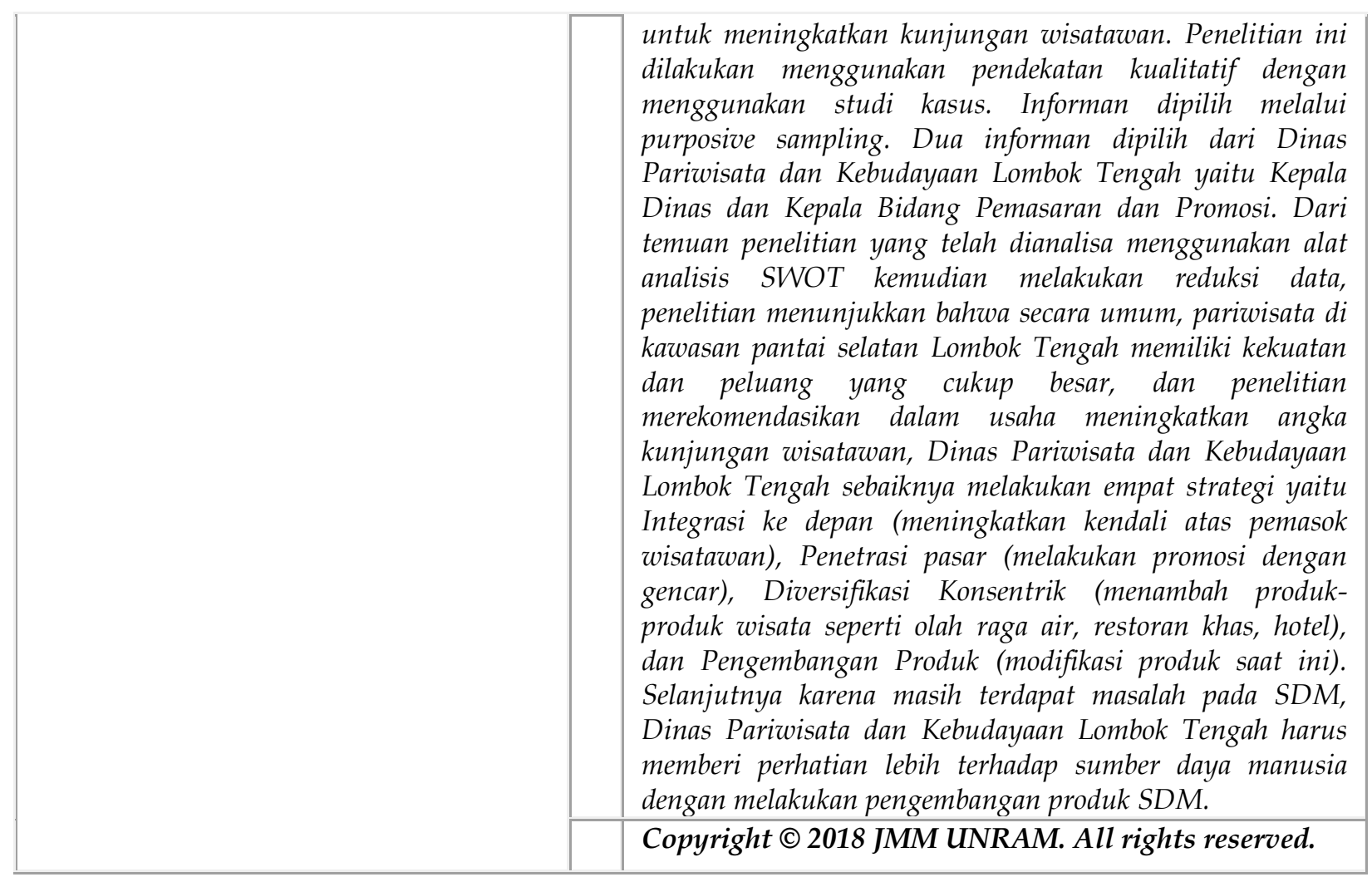

\section{PENDAHULUAN}

Seperti diketahui Nusa Tenggara Barat khususnya Lombok berada di koridor V sebagai pintu gerbang pariwisata dalam MP3EI. Sebagai salah satu gerbang pariwisata nasional provinsi Nusa Tenggara Barat memiliki beberapa Kawasan Strategis Pariwisata Nasional (KSPN). Kawasan inti dari KSPN Mandalika merupakan kawasan pantai selatan Kabupaten Lombok Tengah. Angka kunjungan wisatawan nusantara maupun asing ke kawasan pantai selatan khususnya dan Lombok Tengah umumnya terus meningkat. Walaupun angka kunjungan tersebut masih belum paralel dengan angka menginap, lama tinggal (Lenght of Stay $=$ LOS) juga masih rendah. Jumlah PAD dari 11 sektor Pajak Daerah Kabupaten Lombok Tengah pada tahun 2016 adalah Rp. 40.321.884.900,-. Dari jumlah tersebut, sektor pariwisata berupa pajak hotel, restoran dan hiburan menyumbang Rp. 11.743.222.956,- atau sebesar 29\%. Strategi yang telah dilaksanakan pemerintah Kabupaten Lombok Tengah adalah pelaksanan core event yang menurut Siahaan (2008) merupakan bentuk diversifikasi pasar dilakukan melalui pengemasan event dengan kombinasi dua atau lebih basis atraksi sehingga diharapkan dapat memperkuat pull-factor bagi destinasi. Menurut Wijaya dan Mustika (2014) langkah yang sebaiknya dilakukan yaitu promosi pariwisata di luar negeri dan mengeksplor Obyek Daya Tarik Wisata (ODTW) yang baru untuk menarik wisatawan mancanegara lebih lama tinggal. Menurut Sumarni (2014), harus ada orang yang beperan aktif merupakan faktor pendukung dalam menyebarkan informasi kepada masyarakat mengenai segala kegiatan pariwisata. Meningkatkan pariwisata Lombok Tengah merupakan tugas semua level pemerintahan dari pusat sampai daerah. Mereka adalah Kementerian Pariwisata, Badan Promosi Pariwisata Daerah (BPPD-NTB), Dinas Kebudayaan dan Pariwisata, Pemegang Hak Pengelolaan Lahan (HPL), Indonesia Tourism Development Corporation (ITDC), Perhimpunan Hotel dan Restoran 


\section{NATIONALLY ACCREDITED JOURNAL - DECREE NO. 21/E/KPT/2018}

Indonesia (PHRI), Himpunan Pramuwisata Indonesia (HPI), Tour Operator (Tour and Travel Agent). Berdasarkan latar belakang tersebut, tujuan dari penelitian ini adalah untuk merumuskan strategi yang diusulkan kepada Dinas Pariwisata dan Kebudayaan Lombok Tengah untuk meningkatkan kunjungan wisatawan di kawasan pantai selatan.

\section{TINJAUAN PUSTAKA}

Menurut David (2006), strategi adalah sarana bersama dengan tujuan jangka panjang hendak dicapai. Strategi akan memaksimalkan keunggulan kompetitif dan meminimalkan keterbatasan bersaing. Menurut Hamel dan Prahalad dalam Rangkuti (2009) strategi merupakan tindakan yang bersifat incremental (senantiasa meningkat) dan terus-menerus, serta dilakukan berdasarkan sudut pandang tentang apa yang diharapkan oleh para pelanggan di masa depan. Strategi hampir selalu dimulai dari "apa yang dapat terjadi" dan bukan dimulai dari "apa yang terjadi". Sejalan dengan terminologi teori di atas, menurut David (2006), strategic management dapat didefinisikan sebagai seni dan ilmu untuk memformulasi, mengimplementasi, dan mengevaluasi keputusan lintas fungsi yang memungkinkan organisasi dapat mencapai tujuannya. Mengapa sektor publik membutuhkan manajemen strategis dalam melaksanakan kegiatannya? Karena sebagai suatu organisasi yang ingin mencapai suatu tujuan, organisasi sektor publik memerlukan rencana strategis untuk mencapai tujuan tersebut yang dirinci dalam program-program dan kegiatan-kegiatan yang dapat bersinergi untuk mewujudkan tujuan tersebut (Joyce, 2003). Aplikasi dari manajemen strategis pada organisasi sektor publik terdiri dari komponen yang sama dengan sektor swasta di antaranya pernyataan misi, pengamatan lingkungan, pengamatan organisasi, sasaran dan implementasi, dan telaah dan monitoring implementasi. Menurut Bryson pada organisasi sektor publik menekankan pada pentingnya proses perumusan strategi (Sedarmayanti, 2003). Formulasi strategi adalah tahap menentukan aktivitas-aktivitas yang berhubungan dengan pencapaian tujuan. Formulasi strategi dapat juga diartikan sebagai serangkaian proses yang terlibat dalam penciptaan atau penentuan strategi organisasi. Perumusan strategi merupakan gabungan antara kondisi eksternal dan internal organisasi saat ini dengan tujuan yang akan dicapai di masa yang akan datang (David, 2006). Berdasarkan penelitian oleh Lubis (2004), strategi yang dibuat hendaknya mempertimbangkan situasi dan keadaan organisasi baik keadaan internal organisasi itu sendiri atau lingkungan mikro organisasi, maupun keadaan eksternal organisasi atau yang dikenal dengan lingkungan makro organisasi. Organisasi yang berjaya dan mampu mempertahankan serta meningkatkan lagi penjulannya ditengah-tengah pesaingnya adalah organisasi yang telah berhasil menetapkan strategi bersaingnya dengan tepat.

\section{METODE PENELITIAN}

Penelitian ini secara spesifik lebih diarahkan kepada penggunaan metode studi kasus. Sebagaimana pendapat Lincoln dan Guba dalam Mulyana (2013), menyebutkan bahwa pendekatan kualitatif dapat juga disebut dengan case study yaitu penelitian yang mendalam dan mendetail tentang segala sesuatu yang berhubungan dengan subjek penelitian.

Fokus penelitian ini berdasarkan framework yang diajukan oleh peneliti sebagai berikut: 


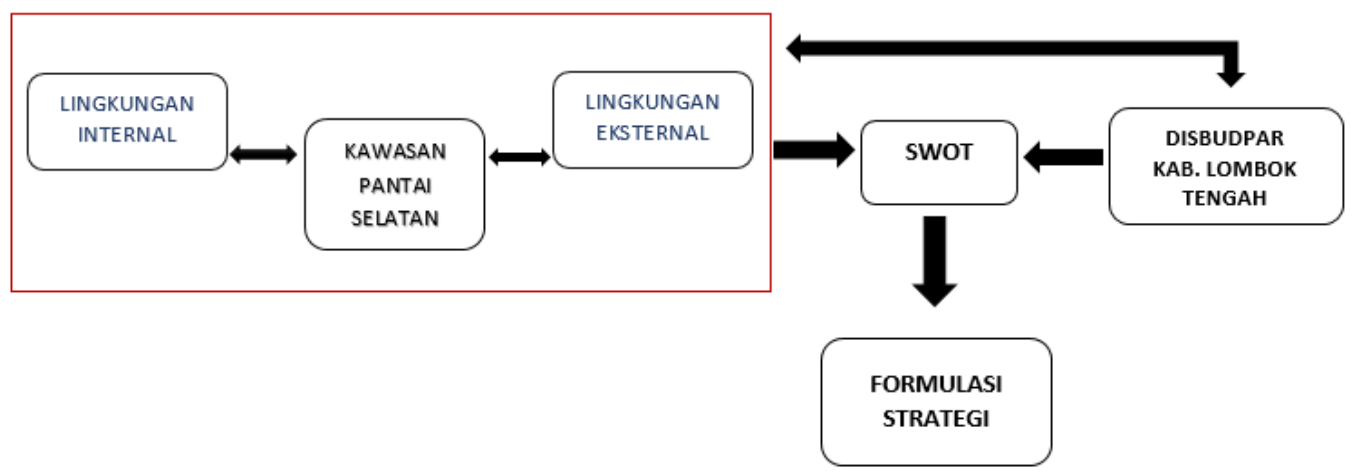

Gambar 1. Framework

Untuk menjawab fokus penelitian, sebagai sumber data utama, peneliti mewawancarai dua orang informan kunci yang telah dipilih melalui purposive sampling yaitu Kepala Dinas dan Kepala Bidang Pemasaran dan Promosi Dinas Pariwisata dan Kebudayaan Lombok Tengah. Selain itu, sumber data pendukung didapatkan dari dokumentasi dari data BPS, buku RIPPARDA, laporan tahunan PAD, data target dan realisasi angka kunjungan, dan pengamatan di lapangan.

Data-data tersebut melewati tahap dua jenis metode triangulasi, yaitu triangulasi data dan triangulasi metodologis. Data yang telah ditriangulasikan kemudian di analisis menggunakan alat analisis SWOT untuk menghasilkan alternatif strategi yang akan direkomendasikan.

\section{TEMUAN PENELITIAN DAN PEMBAHASAN}

\subsection{Analisis Lingkungan Internal}

Berdasarkan Hill \& Jones (2001), lingkungan internal terdiri dari Identifikasi kekuatan dan Identifikasi kelemahan. Pariwisata di kawasan pantai selatan Lombok Tengah sangat diuntungkan oleh keadaan alamnya yang menawan. Sepanjang garis pantai yang membentang dari Pantai Kuta sampai Pantai Tanjung Ann memiliki karakter yang berbeda, hal itu menambah nilai jual pariwisata di pantai selatan karena wisatawan mempunyai opsi yang berbeda-beda saat berkunjung di satu ODTW. Bukan cuma itu, kawasan pantai selatan memiliki wisata adat budaya yang berlokasi di Desa Adat Sade dan Ende. Desa tersebut merupakan Desa tradisional Suku Sasak yang masih mempertahankan adat dan budayanya, bahkan bangunan tradisional masih dirawat dengan baik. Apalagi para agen perjalanan menjadikan kawasan pantai selatan sebagai salah satu destinasi utama wisatawan ke Lombok. Kawasan ini sudah pasti masuk dalam rencana perjalanan wisatawan di mayoritas agen perjalanan. Namun, masih terdapat kekurangan yang menjadi pekerjaan rumah Dinas Pariwisata dan Kebudayaan Kabupaten Lombok Tengah selaku lembaga yang berwenang langsung pada pariwisata di kawasan pantai selatan. Berdasarkan hasil analisis yang dilakukan, kawasan pantai selatan sesungguhnya mengalami keterbatasan dalam hal antara lain; (1) Sumber Daya Manusia Profesional. Hal itu disebabkan oleh keterbatasan jumlah lembaga pariwisata yang ada di Lombok Tengah. Langkah inisiatif dilakukan Dinas Pariwisata Lombok Tengah dengan membentuk Kelompok Sadar Wisata dan pelatihan wirausaha, namun belum mayoritas menghasilkan masyarakat sadar wisata. (2) Jumlah kamar penginapan yang tersedia tidak berbanding lurus dengan angka jumlah kedatangan 


\section{NATIONALLY ACCREDITED JOURNAL - DECREE NO. 21/E/KPT/2018}

wisatawan yang terus meningkat. Hal tersebut berpengaruh pada tingkat Length Of Stay wisatawan. Frekwensi lama menginap wisatawan di Lombok Tengah di bawah target yang ditetapkan. Kekurangan tersebut sampai saat ini masih dikerjakan oleh Dinas Pariwisata Lombok Tengah yang bekerjasama dengan ITDC dalam membangun pariwisata di kawasan pantai selatan. Sampai penelitian ini berjalan, ITDC sudah melakukan kerja nyata dengan membangun kawasan Pantai Kuta dan sekitarnya walaupun belum semua lahan yang ditargetkan clean and clear. Kemajuan ITDC sampai saat ini ialah dengan ditandatanginany Land Intended Development Agreement (LIDA) oleh beberapa investor yang akan membangun hotel berbintang di kawasan pantai selatan, antara lain Royal Tulip yang akan membangun hotel berkapasitas 250 kamar, Pullman 250 kamar, Club Med 350 kamar, Paramount Hotel and Resorts 415 kamar dan Louvre Hotel Group 200 kamar. Dengan demikian pembangunan tersebut diharapkan akan mengatasi masalah tingkat Length Of Stay yang dihadapi Dinas Pariwisata Lombok Tengah.

\subsection{Analisis Lingkungan Eksternal}

Analisis lingkungan eksternal digunakan untuk mengindentifikasi peluang dan ancaman yang mungkin terjadi. Analisis lingkungan eksternal terdiri dari analisis industri pariwisata secara umum, analisis industri pariwisata dalam negeri, dan lingkungan makro (kekuatan ekonomi, kekuatan sosial, budaya, demografis dan lingkungan, kekuatan politik, pemerintahan dan hukum, kekuatan teknologi dan kekuatan kompetitif) (Hill \& Jones, 2001). Ada beberapa peluang yang dimiliki oleh Dinas Pariwisata Lombok Tengah khususnya dikawasan pantai selatan Lombok Tengah. Sebagian besar wisatawan mancanegara yang datang ke Lombok dan Lombok Tengah memiliki tujuan untuk berlibur. Hal ini menandakan Lombok masih memiliki daya tarik wisata tersendiri. Banyaknya objek dan daya tarik wisata di Lombok Tengah apalagi di kawasan pantai selatan masih menjadi daya tarik tersendiri bagi para wisatawan untuk datang ke Lombok. Hal ini membuka peluang bagi pariwisata di kawasan pantai selatan Lombok Tengah untuk memperoleh banyak tamu sehingga dapat meningkatkan tingkat kunjungan wisatawan. Peluang lain yang dimiliki oleh Dinas Pariwisata Lombok Tengah pada masa mendatang adalah peluang untuk berkembang lebih baik dengan adanya dukungan dari pemerintah NTB. Dalam rangka otonomi daerah, sektor pariwisata dijadikan leading sector bagi pendapatan daerah. peluang yang dapat diraih oleh Dinas Pariwisata Lombok Tengah untuk meningkatkan kunjungan wisatawan di kawasan pantai selatan berdasarkan uraian analisis eksternal adalah peluang untuk membidik konsumen, baik individu maupun suatu badan, yang sering melakukan kegiatan wisata, seminar dan kegiatan sejenis agar menggunakan hotel-hotel di Lombok sebagai tempat kegiatan sekaligus tempat menginap para peserta apalagi saat ini kawasan pantai selatan sudah mulai membangun hotel-hotel berkelas dengan telah ditandatanganinta LIDA.

Disamping peluang-peluang, terdapat pula ancaman-ancaman yang harus dihadapi oleh Dinas Pariwisata Lombok Tengah. Kondisi ekonomi yang belum stabil merupakan ancaman yang cukup serius bagi bagi industri pariwisata di Lombok karena berpengaruh langsung terhadap keuangan wisatawan domestik. Hal ini berdampak langsung pada keuangan pemerintah daerah padahal jumlah tamu yang datang masih tergolong sedikit. Ancaman lain yang dihadapi kondisi politik dan keamanan dalam negeri yang tidak kondusif. Hal itu diperparah dengan terjadinya gempa bumi skala besar pada 26 Juli 2018 skala 6.4 SR, 5 Agustus 2018 skala 7.0 SR dan 19 Agustus 2018 skala 6.9 SR melanda Lombok dengan ribuan gempa susulan yang tercatat oleh BMKG. Dari itu khalayak menjadi sadar bahwa Lombok 


\section{NATIONALLY ACCREDITED JOURNAL - DECREE NO. 21/E/KPT/2018}

merupakan daerah yang rawan gempa bumi. Ancaman lain yang dihadapi oleh industri pariwisata di Lombok adalah kekuatan tawar menawar wisatawan yang cukup besar, dan persaingan antar perusahaan/investor dalam industri pariwisata dalam situasi pariwisata. Kedua ancaman tersebut dapat menyebabkan perubahan struktur persaingan dalam industri pariwisata dan kemungkinan dapat menimbulkan persaingan yang tidak sehat karena jumlah tamu yang datang ke Lombok masih tergolong sedikit. Analisis eksternal yang menyiratkan adanya peluang-peluang bagi Dinas Pariwisata Lombok Tengah secara khusus. Kemajuan teknologi informasi seperti internet dan e-commerce memberikan peluang bagi kawasan pantai selatan Lombok Tengah untuk mempromosikan pariwisatanya dengan lebih baik yang mencakup seluruh dunia. Peluang lain yang dimiliki oleh kawasan pantai selatan Lombok Tengah adalah kemungkinan menjadi market leader dalam sektor wisata bahari di Lombok karena di satu kawasan memiliki pilihan ODTW yang beragam dan memiliki keunikan masing-masing, selain itu kawasan pantai selatan telah dicanangkan sebagai Kawasan Ekonomi Khusus di Lombok, kemudian pembangunan yang gencar dilakukan oleh ITDC dan dapat masih terus berkembang di hari depan.

\subsection{Hasil Analisis SWOT}

Analisis SWOT dalam penelitian ini menggunakan metode kualitatif di mana akan membentuk tabel matriks yang berisi alternatif strategi berdasarkan keadaan masing-masing dari S (Strength/kekuatan), W (Weakness/kelemahan), O (Opportunities/peluang), dan T (Threats/ancaman). Tujuan dari setiap analisis SWOT adalah untuk mengidentifikasi faktor kunci

yang datang dari lingkungan internal dan eksternal. Dalam alat analisis SWOT dibagi menjadi faktor internal yang terdiri dari Strength (Kekuatan) dan Weakness (Kelemahan), kemudian faktor eksternal yang terdiri dari Opportunities (Peluang) dan Threats (Ancaman). SWOT adalah identifikasi berbagai faktor secara sistematis untuk merumusakan strategi pelayanan. Analisis ini berdasarkan logika yang dapat memaksimalkan peluang namun secara bersamaan dapat meminimalkan kekurangan dan ancaman yang menghasilkan empat kemungkinan alternatif strategi yaitu SO, ST, WO, dan WT (Rangkuti, 2006), seperti terlihat pada gambar di bawah;

\begin{tabular}{|l|l|l|}
\hline $\begin{array}{l}\text { Tabel 1.Matrik } \\
\text { SWOT Faktor-faktor } \\
\begin{array}{l}\text { Internal dan } \\
\text { faktor eksternal }\end{array}\end{array}$ & $\begin{array}{l}\text { Kekuatan (S) } \\
\text { Daftarkan 5-10 } \\
\text { faktor-faktor internal }\end{array}$ & $\begin{array}{l}\text { Kelemahan (W) } \\
\text { Daftarkan 5-10 } \\
\text { faktor-faktor } \\
\text { eksternal }\end{array}$ \\
\hline $\begin{array}{l}\text { Peluang (O) } \\
\text { Daftarkan 5-10 } \\
\text { faktor-faktor } \\
\text { peluang eksternal }\end{array}$ & $\begin{array}{l}\text { Strategi (SO) } \\
\text { Buat strategi disini } \\
\text { yang menggunakan } \\
\text { kekuatan untuk } \\
\text { memanfaatkan } \\
\text { peluang }\end{array}$ & $\begin{array}{l}\text { Strategi (WO) } \\
\text { Buat strategi disini } \\
\text { yang memanfaatkan } \\
\text { peluang mengatasi } \\
\text { ancaman }\end{array}$ \\
\hline $\begin{array}{l}\text { Ancaman (T) } \\
\text { Daftarkan 5-10 } \\
\text { faktor-faktor } \\
\text { ancaman eksternal }\end{array}$ & $\begin{array}{l}\text { Strategi (ST) } \\
\text { Buat strategi disini } \\
\text { yang menggunakan } \\
\text { kekuatan untuk } \\
\text { mengatasi ancaman }\end{array}$ & $\begin{array}{l}\text { Strategi (WT) } \\
\text { Buat strategi disini } \\
\text { yang meminimalkan } \\
\text { kelemahan dan } \\
\text { menghindari } \\
\text { ancaman }\end{array}$ \\
\hline
\end{tabular}

Gambar 2. Matriks SWOT dalam Rangkuti (2006) 
Strategi SO
a. Penguatan pasar
b. Penetrasi pasar
c. Pengembangan Produk
d. Integrasi ke depan
e. Integrasi ke belakang
f. Integrasi horizontal

Strategi WO
a. Penguatan pasar
b. Penetrasi pasar
c. Pengembangan produk
d. Integrasi horizontal
e. Penciutan bisnis
f. Pengurangan

\section{Strategi ST}

\author{
a. Diversifikasi Konsentrik \\ b. Diversifikasi horizontal \\ c. Diversifikasi konglomerasi \\ d. Usaha patungan \\ e. Outsourcing \\ f. Benchmarking
}

Strategi WT
a. Penciutan bisnis
b. Likuidasi
c. Diversifikasi konsentrik
d. Diversifikasi horizontal
e. Diversifikasi konglomerasi
f. Pengurangan

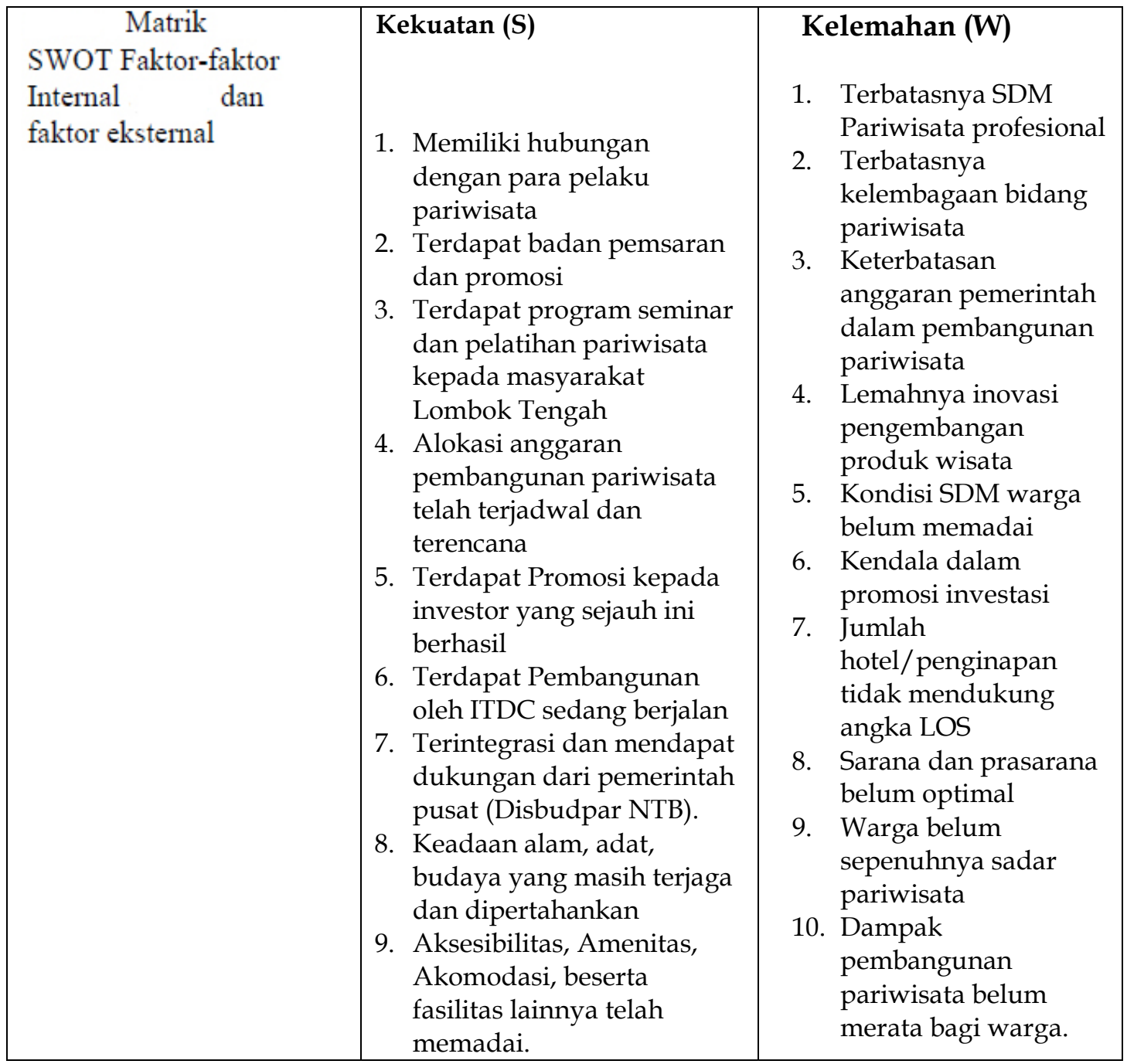




\section{NATIONALLY ACCREDITED JOURNAL - DECREE NO. 21/E/KPT/2018}

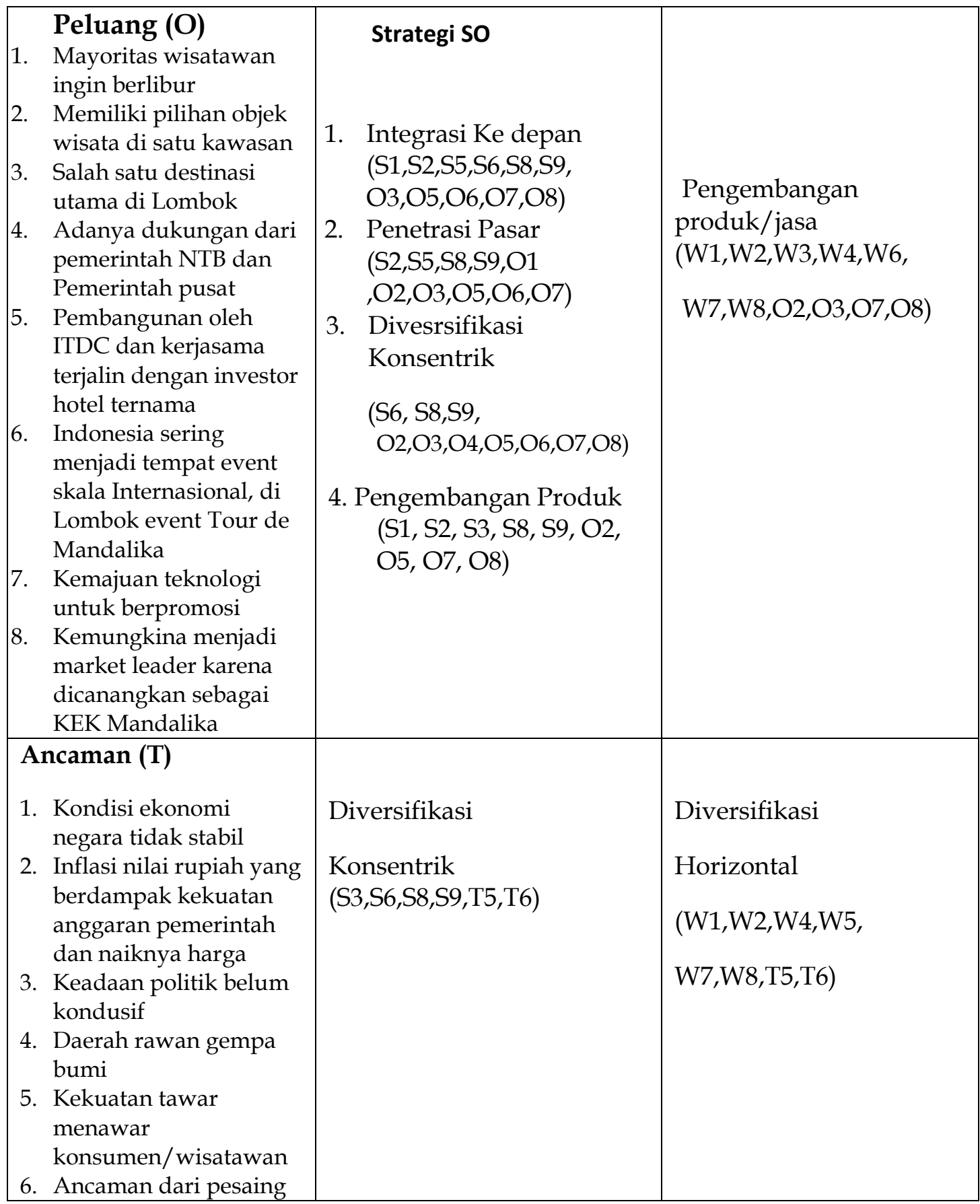

Gambar 3. Hasil analisis SWOT

\subsection{Perumusan Strategi}

Melihat faktor internal dan eksternal yang dimiliki oleh Dinas Pariwisata Lombok Tengah dalam usahanya meningkatkan kunjungan wisatawan di kawasan pantai selatan Lombok Tengah, sebenarnya memiliki kekuatan dalam bersaing, hasil analisis ini didasarkan pada dua dimensi evaluatif yaitu posisi bersaing dan pertumbuhan pasar. Dinas Pariwisata Lombok Tengah memiliki kekuatan daya saing serta didukung oleh keadaan eksternal yang bila 


\section{NATIONALLY ACCREDITED JOURNAL - DECREE NO. 21/E/KPT/2018}

strategi dilakukan dengan baik, kawasan pantai selatan Lombok Tengah bisa menjadi market leader industri pariwisata di Lombok. Strategi utama yang bisa dilakukan Dinas Pariwisata Lombok Tengah antara lain; Pertama, Strategi Diversifikasi Konsentrik dengan menambah produk/jasa baru untuk menunjang kegiatan wisata yang sudah ada. Kedua, Strategi Integrasi Ke Depan dengan menjual produk secara langsung kepada konsumen/wisatawan. Ketiga, Strategi Penetrasi Pasar, setelah melakukan strategi integrasi ke depan, penetrasi pasar yaitu melakukan pemasaran dan promosi dengan lebih gencar dengan menambah alat promosi atau media promosi, mungkin saja di satu media tapi menyajikan beberapa berita pemasaran. Keempat, Strategi Pengembangan Produk, strategi ini bisa meningkatkan penjualan dengan memperbaiki atau memodifikasi produk/jasa yang sudah ada sebagai langkah terakhir dari tiga strategi sebelumnya. Dengan demikian strategi yang tepat dilakukan oleh Dinas Pariwisata Lombok Tengah adalah Strategi S-O pada Matriks SWOT. Empat strategi di atas berbeda dengan usulan yang dikemukakan oleh

\section{KESIMPULAN}

Dalam analisis eksternal Dinas Pariwisata Lombok Tengah dilakukan analisis macroenvironment organisasi, analisis industri pariwisata secara umum, analisis industri pariwisata dalam negeri. Dari analisis macroenvironment organisasi dapat diambil kesimpulan bahwa Dinas Pariwisata dan Kebudayaan Lombok Tengah sebenarnya memiliki peluang yang cukup besar dari pariwisata di kawasan pantai selatan. Di samping terdapat ancaman, namun peluang yang dimiliki lebih berpotensi dalam kemajuan pariwisata di kawasan tersebut.

Dari analisis internal organisasi dapat diambil kesimpulan bahwa kelemahan yang dimiliki Dinas Pariwisata dan Kebudayaan Lombok Tengah hanya dari segi SDM. Kelemahan itu sekiranya mampu ditutupi dengan berbagai kekuatan yang dimiliki. Dinas Pariwisata Lombok Tengah cukup unggul pada struktur organisasi sehingga pembagian kerja menjadi terfokus di masing-masing bidang fungsional.

Hasil analisis SWOT setelah mempertimbangkan kedua lingkungan di atas, bahwa ada empat strategi yang direkomendasikan dari penelitian ini bagi Dinas Pariwisata dan Kebudayaan Lombok Tengah untuk meningkatkan kunjungan wisatawan, Integrasi ke depan, Penetrasi pasar, diversifikasi konsentrik, dan Pengembangan produk.

Melengkapi penelitian ini, perhatian diberikan oleh peneliti kepada Dinas Pariwisata Lombok Tengah harus memberi perhatian lebih terhadap sumber daya manusia yang dimiliki oleh Dinas Pariwisata Lombok Tengah karena dalam setiap organisasi, interaksi sumber daya manusia akan sangat mempengaruhi penilaian wisatawan terhadap ODTW tersebut termasuk Dinas Pariwisata Lombok Tengah dalam mengimplementasikan strateginya.

\section{Ucapan Terima Kasih}

Kepada Suami dan anak-anakku yang tercinta atas dukungan dan kesabaran selama saya melaksanakan penelitian ini, dan juga kepada Ibu dan keluarga besar saya. Kepada Bapak/Ibu Dosen pembimbing yang dengan sabar dan penuh keikhlasan membimbing, sehingga tesis ini bisa terselesaikan. 


\section{NATIONALLY ACCREDITED JOURNAL - DECREE NO. 21/E/KPT/2018}

\section{REFERENSI}

Badan Pusat Statistik Kabupaten Lombok Tengah, Lombok Tengah Dalam Angka Tahun 2012 s/d 2016, Praya.

David , F. R., (1995), Strategic Management, Fivth Edition, Prentice Hall.

David, F. R. (2006). Manajemen Strategis,Penerbit Salemba Empat, Jakarta.

Dinas Kebudayaan dan Pariwisata Kabupaten Lombok Tengah.(2013), Rencana Induk Pengembangan Pariwisata Daerah (RIPPDA), 2013, Praya.

Goldsmith, R. E. (2012). Strategy In Tourism Service. Florida State University, USA: Emerald Group Publishing Limited.

Goranczewski, B. (2010). SWOT Analysis In The Formulation Of Tourism Development Strategies For Destinations. Tourism, Vol. 20, N0. 2.

Hill. C.W.,\& Jones. G.R. (2001). The Strategic Management Process. Houghton Mifflin Company. Boston USA.

Hudson, S. (2008). Tourism and Hospitality Marketing. SAGE Publication Asia-Pasific Pte Ltd. Singapore.

Hunger, D. K., \&Wheelen. T.L. (2003). Manajemen Strategis. Penerbit Andi. Yogyakarta.

Joyce E.A. (2003). Human resource management (An Experimental Approach International Edition). Mc. Graw-Hill Inc. Singapore

Lewis. J., \& Ritchie, J. (2003). Qualitative Research Practice: A Guide for Social Science Students and Researchers. Sage Publications, London.

Lubis, A. N. (2004). Strategi Pemasaran Dalam Persaingan Bisnis. USU Digital Library.

Marrus. S. K, (2002).Desain Penelitian Manajemen Strategik, Rajawali Press, Jakarta.

Moelong, Lexi,J.(2000), Metode Penelitian Kualitatif, PT. Remaja Rosdakarya, Bandung.

Rangkuti, F. (2006). Analisis SWOT : Teknik Membedah Kasus Bisnis. PT Gramedia Pustaka Utama. Jakarta

Rangkuti, F. (2009). Strategi Promosi yang Kreatif dan Analisis Kasus Integrated Marketing Communication. PT.Gramedia PustakaUtama, Jakarta.

Ring P.S., \& Perry, J.L. (1985). Strategic Management In Public and Private Organizations: Implications and Distinctive Contexs and Constrains.Academy of Management Review.

Sedarmayanti, (2003), Sumber Daya Manusia dan Produktivitas Kerja, Penerbit Ilham Jaya, Bandung.

Siahaan, S. L. (2008). VISIT INDONESIA YEAR 2008: SUATU TINJAUAN DARI PERSPEKTIF PEMASARAN DESTINASI PARIWISATA. Majalah Ilmiah Panorama Nusantara.

Sumarni. (2014). Strategi Promosi Dinas Kebudayaan dan Pariwisata Provinsi Kalimantan Timur dalam Mensosialisasikan Program Visit East Kalimantan. Manajemen Pariwisata, Vol. 14, No. 2.

Wijaya, I. B. P., \& Mustika, M. D. S. (2014). Pengaruh Jumlah Kunjungan Wisatawan,Lama Tinggal Dan Pengeluaran Wisatawan Mancanegara Terhadap Pendapatan Sector Perdagangan,Hotel Dan Restoran Provinsi Bali (2000-2012). E-Jurnal Ekonomi Pembangunan Universitas Udayana.

--------, Pemerintah Provinsi Nusa Tenggara Barat, Peraturan Daerah Provinsi Nusa Tenggara Barat Nomor 7 Tahun 2013 Tentang Rencana Induk Pembangunan Kepariwisataandaerah Tahun 2013-2028. 